\title{
The Use of Data Analysis of Information and Communication Technologies in the Preparation of Engineering Specialties
}

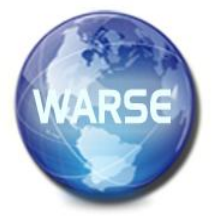

\author{
Smirnova Z.V. ${ }^{1}$, Bystrova N.V.,", , Kytepov M.M. ${ }^{3,}$ Kaznacheeva S.N. ${ }^{4}{ }^{4}$ Kutepova L.I. ${ }^{5}$ \\ ${ }^{1}$ Minin Nizhny Novgorod State Pedagogical University, Nizhny Novgorod, 603005, Russia \\ smirnovazv@mail.ru \\ ${ }^{2}$ Minin Nizhny Novgorod State Pedagogical University, Nizhny Novgorod, 603005, Russia \\ bystrova@mail.ru \\ ${ }^{3}$ Minin Nizhny Novgorod State Pedagogical University, Nizhny Novgorod, 603005, Russia \\ kytepovmm@mail.ru \\ ${ }^{4}$ Minin Nizhny Novgorod State Pedagogical University, Nizhny Novgorod, 603005, Russia \\ kaznacheeva@mail.ru \\ ${ }^{5}$ Minin Nizhny Novgorod State Pedagogical University, Nizhny Novgorod, 603005, Russia \\ kytepova_li@mail.ru
}

\begin{abstract}
In the article, the author considers innovative technologies for training teachers in vocational education, considers the solution to these problems depending on the content and training technology of future engineering specialists. At the present stage of the development of society, the social need for creative thinking outside the box has grown more than ever. The need for creative activity of a specialist and developed technical thinking, in the ability to design, evaluate, rationalize equipment and technology is growing rapidly. In many ways, the solution to these problems depends on the content and technology of training future specialists in engineering specialties. The article explores the problem of training professional education teachers in engineering disciplines. The modern technologies of vocational training are considered, the essence of training technologies in vocational - pedagogical education in educational institutions, the quality of training of specialists in engineering and technical specialties is increased.
\end{abstract}

Key words: data analysis, professional education, innovative technologies, engineering and technical specialties

\section{INTRODUCTION}

Optimization of education at the present stage of development is closely related to the development trends of educational technologies in professional activity, which contributes to the self-actualization and self-realization of the individual [1-3].

The concept of innovative technology implies an educational aspect related to the formation and development of personal qualities of students in their professional activities.

Innovative educational technologies are accompanied by specialists in engineering and technical specialties is analyzed, the basic principles and objectives of the study of vocational education for the training of specialists in engineering specialties are highlighted [4-6]. Therefore, this article discusses the problems of the formation of the content of the educational process for the training of specialists in engineering specialties. The analysis of the use of innovative technologies for the training of teachers of vocational training in engineering and technical specialties at the university. Applying innovative technologies of professional teacher education, in the process of research, organizational and pedagogical conditions for training teachers for a professional school were developed. Innovative forms of teacher training for a professional school are considered. Guided by the results of experimental work, we came to the conclusion that, applying innovative

the results of scientific research in the field of professional training. So for example, the development of information and communication technologies has led to the development of programmed learning; the result of the study is the natural development of human thinking, which led to the use of problem-based learning; activity approach.

The development trend of modern educational technologies is directly related to the Germanization of vocational education, which contributes to self-actualization and self-realization of the individual.

At the present stage, innovative teaching technologies are considered as a systematic method for creating, applying and defining a learning process and mastering knowledge using technical and human resources and their interaction. In the professional activity of a teacher, some forms and methods of active learning, which make the learning process torn to pieces, are being replaced by holistic educational teaching technologies. At the same time, the technological process of the training process will consist in the fact that the educational process is completely 
manageable [5].

Pedagogical technologies in the process of a teacher's professional activity can be characterized by the following criteria:

Firstly, pedagogical technology negates pedagogical impromptu in practical activities and puts it on the path of preliminary design of the educational process with the subsequent implementation of the project in a group. (Learning Technology) [14]

Secondly, the pedagogical process, in contrast to the previously used developments in the learning process, offers a project of the educational process, which determines the structure and content of the student's activities, thus designing the educational and cognitive activity leads to the achievement of each student

Thirdly, an essential feature of pedagogical technology is the process of goal formation. This is the central problem of pedagogical technology in contrast to traditional pedagogy. It is considered in two aspects [7-11]:

1) diagnosis of goal formation and objective quality control of assimilation by students of educational material;

2) the development of the personality as a whole.

Fourth, thanks to the idea of the subject of pedagogical technology as a project of a certain pedagogical system, it is possible to formulate an important principle for the development of pedagogical technology and its implementation in practice - the principle of integrity (structural and substantial) of the entire educational process. The principle of integrity is the harmony of all elements of the pedagogical system [2].

Innovative teaching technologies are considering a certain way of vocational training, this method is aimed at implementing functions using training tools under the control of a person.

The leading role in learning technology is given to learning tools $[13,15]$ :

in this case, the teacher does not educate students, but performs the function of stimulating and fixing their actions, as well as the function of managing learning tools. The main task of the pedagogical skill of the teacher is to choose the right content, apply the best teaching methods and means in accordance with the content of the training program and the assigned pedagogical tasks $[6,7]$.

Thus, the new requirements of society for the training of specialists in engineering and technical specialties, lead to the need to change educational technologies.

Nowadays, more relevant and productive are innovative technologies that allow you to organize the educational process taking into account the professional orientation of the learning process. And also aimed at the interests of the student in their professional activities.

The task of modern education is not only to release a specialist who has received high-level training, but also to include him at the stage of training in the development of new technologies, adapt to the conditions of a specific production environment, make him capable of making new decisions, and also successfully performing the functions of a manager.

The implementation of these priority requirements is facilitated by pedagogical innovation. Innovations in educational activity are the use of new knowledge, techniques, approaches, technologies to obtain results in the form of educational services that are distinguished by social and market demand [12].

A study of the use of innovative technologies in professional activities shows that the majority is devoted to the development of training technologies.

An analysis of the scientific and pedagogical literature shows that innovative learning models are based on the concept of developing [1].

\section{MATERIALS AND METHODS}

One of the $\mathrm{x}$ disciplines in engineering education is "Descriptive Geometry and Engineering Graphics", on the basis of this we examined the goals that students need to achieve when studying it and the elements that students need to master to achieve these goals in a quality manner. In order to make student learning as effective as possible, it is proposed to use interactive learning technologies that increase students' independence in completing assignments.

\section{Neural Networks in Data Mining}

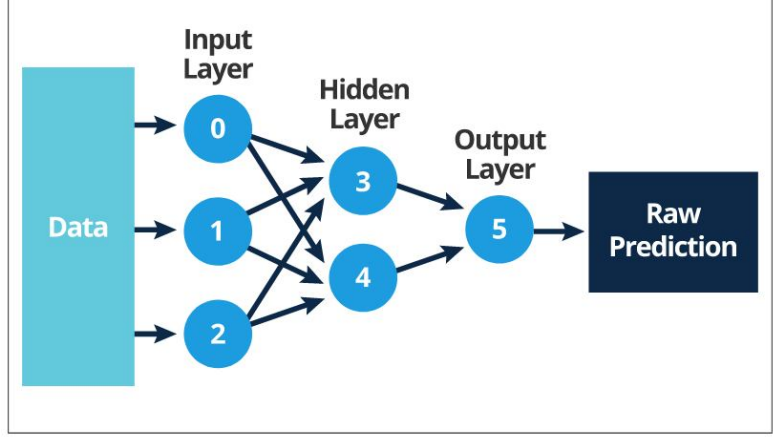

Figure 1: Using neural network for data mining

To this end, there were innovative forms and methods of work aimed at enhancing the independent work of students both in classroom and extracurricular settings [2].

In extracurricular activities, tasks are solved, preparation for laboratory and practical classes, work with educational and controlling electronic resources (figure $1)$.

The article describes the development of the use of interactive technologies in the process of studying material in the discipline "Descriptive geometry and engineering graphics." With the introduction of these methods, the independent work of students is supported [17-20].

As some of the results of educational practice implemented in the classroom, it should be noted that despite the positive attitude of students to the proposed topics of research, few students undertook their implementation, motivating this by congestion in other disciplines [3].

Therefore, it is advisable to abandon the practice of planning design and research tasks for each discipline separately. 
Based on the analysis of theoretical research literature, it was possible to determine that the use of innovative technologies in the training of specialists in engineering and technical specialties at the present stage is a dynamically developing system that is based on the basic principles of modernization of vocational education: integration of general and vocational education; multilevel vocational education; the creation of intensive flexible learning systems that provide high quality educational and vocational training, the realization of all potential opportunities and abilities of a person; the transition from a technocratic approach to the development of a system of vocational and pedagogical education to socio-pedagogical, humanitarian; the formation and development of personality in a continuous and holistic process of professional and pedagogical training on the basis of humanitarian, natural sciences, general professional and special education [21, 22].

In accordance with the purpose of applying innovative technologies in vocational education, we examined the relationship of such technologies in the educational activity of a teacher diagram (figure 2).

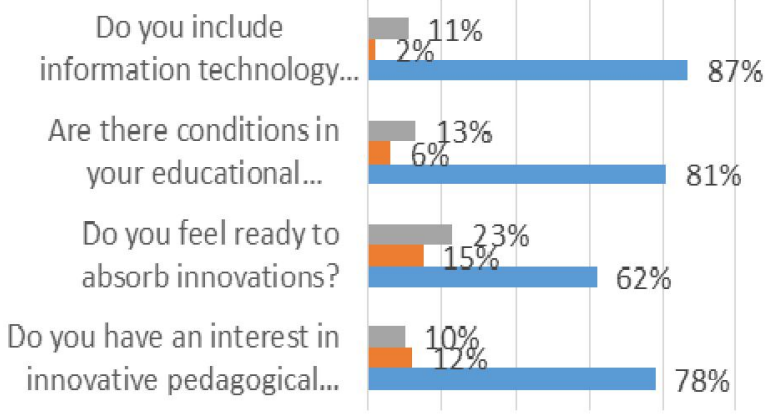

\section{$\begin{array}{lllll}0 \% \quad 20 \% & 40 \% \quad 60 \% \quad 80 \% & 100 \%\end{array}$ - Partially Not $\square$ Yes}

Figure 2: Analysis of profiles of teachers on the use of innovative technologies in professional activities.

According to the results of the questionnaire, we see that a hundred and a large part of vocational training teachers $78 \%$ of respondents are interested in the use of innovative technologies in professional activities, $81 \%$ have the opportunity to carry out innovative educational activities in the educational institution (figure 2).

Considering the specific subject "Descriptive Geometry and Engineering Graphics", which is carried out by innovative technologies, it should be noted that several methods are used for interactive teaching in the classroom:

- methods of exponential presentation (here, visual support is used in the form of graphic images of concepts on a plane, students perform tasks of a variable nature (drawings) using computer graphics) [23];

- the use of cognitive-reproductive and stimulating-search binary method (due to this, the teacher encourages the student to perform mental and objective actions in three-dimensional space) [24].

For an effective teaching method using a specific teaching methodology, it will be much more convenient for a vocational education teacher to manage the educational process through information technology - the Moodle electronic system.

Such an information system has already established itself in the NGPU them. TheMinin. university has organized an electronic educational environment in which the teacher can post any information on readable disciplines.

The development of educational and methodological information in the discipline "Descriptive Geometry and Engineering Graphics" meets all the requirements of the educational content. Picture 1.

As can be seen in Figure 1, the teacher gives the material in the form of lectures, after which the student is invited to take a test and a mini-survey, and then you need to complete an individual task. With the help of such tools, the teacher can more quickly check the work performed and respond to it, competently and productively managing the process $[25,26]$.

Thus, we can state: innovative technologies of vocational and pedagogical education in engineering disciplines should be focused on the formation of an image of an individual adequate to the content of professional activity. It is important to note that the creation of intensive flexible training systems that provide high quality educational and vocational training is built on the realization of all potential opportunities and abilities of a person is determined by the principle of multidisciplinary, which is implemented in expanding the content of education, professional training profiles, in the didactic completion of each level of training, the formation of such a specialist, who would master several specializations and could get the necessary the first level of education to produce the appropriate certificate that meets the state standard [27]. In this regard, we got a good result of the quality of training students using information technologies in the electronic educational environment of Moodle. The experiment was attended by students of the correspondence department of the faculty of management and social and technical services, studying in the direction of preparation Technical maintenance of road transport (34 people).

Table 1: The result of evaluating the effectiveness of training using innovative technologies.

\begin{tabular}{|c|c|c|c|}
\hline & $\begin{array}{c}\text { Performance } \\
\text { indicator }\end{array}$ & $\begin{array}{c}2018 \\
\%\end{array}$ & $\begin{array}{c}2019 \\
\%\end{array}$ \\
\hline Descriptive & Great and good & $67 \%$ & $89 \%$ \\
Geometry and & & & \\
Engineering & & & \\
Graphics & & & \\
\hline
\end{tabular}

From table 1 of the results of the quality of training it should be concluded that the assessment of the effectiveness of training specialists in engineering disciplines increases from $67 \%$ to $89 \%$.

In this regard, the urgent task of applying innovative technologies in vocational - pedagogical education is the orientation of graduates to continuous personal and professional development; such an approach corresponds to the essence and specificity of pedagogical activity in complex, constantly changing professional and social conditions [28]. 
The solution to this urgent problem requires the introduction of innovative learning technologies. Innovative learning technologies should be considered as a tool with which a new educational paradigm can be implemented.

The main goal of innovative educational technologies is to prepare a person for life in an ever-changing world. The essence of such training is to orient the educational process towards the potential of a person and their implementation.

Among innovative technologies, training technologies based on personal and activity approaches (personality-oriented, personality-developing, activity-based learning technologies) are now the most developed.

At present, the importance of a person's preparedness for actions, the result of which is not a foregone conclusion, is increasing. In professional activities, in human life more and more often unpredictable situations arise, characterized by a greater degree of uncertainty. Modern experts are required qualities, abilities that allow you to find solutions in planned situations. Only a person can go beyond the normative, well-established state of affairs, take responsibility for the activities performed.

\section{CONCLUSION}

The study showed that increasing the requirements for the quality of training of specialists in engineering disciplines is becoming an urgent problem and a condition for the development of the vocational education system, an incentive for updating the content of vocational and pedagogical education based on the principles of fundamental, universality, integrativity, variability, continuity, continuity and its practical orientation.

The study of urgent problems allows us to determine the main tasks of development: strengthening the interconnections of the system of professional and pedagogical education using innovative technologies in training specialists with an engineering and technical focus and the needs of society; improving the quality of training of professional - teaching staff; providing the content of professional and pedagogical education, means, forms and methods of training and education at all levels of professional activity; development of the material and technical base and scientific and methodological support, providing an increase in the level of information culture in vocational and pedagogical education; stimulation of the development and implementation of new information technology in the process of training professional teaching staff.

The study showed that in the context of the development of innovative technologies in the framework of informatization, the goals of professional and pedagogical education are: the implementation of methodological approaches to vocational training, reliance on innovation in the field of structure.

Thus, the training of specialists in vocational and pedagogical education in engineering disciplines is directly related to the development of new forms and methods of instruction.

\section{REFERENCES}

1. Z.V. Smirnova. Forecasting and planning in the field of service Teaching aid // Vesknik of Minin University 2019.

2. Z.V. Smirnova, O.I. Vaganova, M.L. Gruzdeva, S.N. Kaznacheeva, M.N. Gladkova. Electronic course development for future engineers training In the collection: IOP Conference Series: Materials Science and Engineering. 2019.S. 012001.

3. O. Vaganova, Z.V. Smirnova, M.A. Karpova. Realization of innovative educational environment of a university//Azimuth of scientific research: pedagogy and psychology. 2019.Vol. 8. No. 2 (27). S. 225-227.

4. Z.V. Smirnova, O.I. Vaganova. Handmarking at higher education institution through electronic-educational environment.//Innovative economy: prospects for development and improvement. 2019.No 3 (37). S. 111-118.

5. V.M. Yurina, O.I. Vaganova, Z.V. Smirnova. Technology of pedagogical support in vocational education.//Innovative economy: prospects for development and improvement. 2019.No 2 (36). S. 121-127.

6. Z.V. Smirnova, K.A. Kochnova. Training of employees of service enterprises using information technologies//Vesknik of Minin University. 2019.Vol. 7. No. 1 (26). S. 5.

https://doi.org/10.26795/2307-1281-2019-7-1-5

7. N.V. Kamenez, Z.V. Smirnova, O.I. Vaganova, N.V. Bystrova, J.M. Tsarapkina. Development of instructing techniques in professional training//International Journal of Mechanical Engineering and Technology. 2019.Vol. 10. No. 2. P. 899-907. 2

8. L.K. Ilyashenko, Z.V. Smirnova, O.I. Vaganova, E.A. Chelnokova, S.N. Kaznacheeva. Ethods of conducting practical training on the subject "power sources for welding"//International Journal of Mechanical Engineering and Technology. 2019.Vol. 10. No. 2. P. 908-917.

9. Z.V. Smirnova. Municipal management of urban economy-educational-methodical manual / Vesknik of MininUniversity, 2018.

10. Z.V. Smirnova, M.L. Gruzdeva, O.G. Krasikova. Open electronic courses in the educational activities of the university// Vesknik of Minin University. 2017. No. 4 (21). S. 3.

11. O. V. Cheremisina, T.E. Litvinova, D.S. Lutskiy. Separation of samarium, europium and erbium by oleic acisolution at stoichiometric rate of extractant. 2019. Innovation-Based Development of the Mineral Resources Sector: Challenges and Prospects - 11th conference of the Russian-German Raw Materials, 2018, pp. 413-419.

12. D. Lutskiy, T. Litvinova, I. Oleijnik, I. Fialkovskiy. Effect of anion composition on the extraction of cerium (Iii) and yttrium (Iii) by oleic acid. 2018. ARPN Journal of Engineering and Applied Sciences, 13 (9), pp. 3152-3161. 
13. D. Lutskiy, T. Litvinova, A. Ignatovich, I. Fialkovskiy. Complex processing of phosphogypsum - A way of recycling dumps with reception of commodity production of wide application. 2018. Journal of Ecological Engineering, 19 (2), pp. 221-225. https://doi.org/10.12911/22998993/83562

14. O. Cheremisina; V. Sergeev; A. Fedorov; A. Iliyna. Problems of protection of urban areas from radionuclides strontium-90 and caesium-137 after technological disasters. Journal of Ecological Engineering WOS:000416833700013. s2.0-85018970033. 2017 (No. 3, V. 18, 2017. P. 97-103.)

15. O. V. Cheremisina; V.V. Sergeev; D.E. Chirkst; T.E. Litvinova. Thermodynamic investigation into extraction of cerium(III) by tributyl phosphate from phosphoric acid solution Russian Journal of Non-Ferrous Metals. WOS:000367519700005. 2 s2.0 - 84952646137

doi: 10.3103/S1067821215060036 (No. 61, V. 56, 2015. Pp. 15-621.)

16. O. V. Cheremisina, V.V. Sergeev, A.T. Fedorov. et al. Metallurgist (2019) 63: 300. https://doi.org/10.1007/s11015-019-00824-9 (July 2019, Volume 63, Issue 3-4, pp. 300-30)

17. O. V. Cheremisina; V.V. Sergeev; D.A. Alferova. Study of iron stripping from dehpasolutionsduring the process of rare earth metals extraction from phosphoric acid. ARPN Journal of Engineering and Applied Science. No. 8, V. 14, 2019. Pp. 1591-1595.

18. O. V. Cheremisina; V.V. Sergeev; D.A. Alferova; A.P. Ilyna. Quantitative X-ray spectral determination of rare-earth metals in products of metallurgy. 2-s2.0-85059. 2018 Journal of Physics: Conference Series: Conference Proceeding Conference Paper. St Petersburg: IOP Publishing, V. 1, 2018. Pp. 1-7.)

19. S.V. Klyuev, S.N. Bratanovskiy, S.V. Trukhanov, H.A. Manukyan. Strengthening of concrete structures with composite based on carbon fiber // Journal of Computational and Theoretical Nanoscience. 2019. V.16. №7. P. 2810 - 2814.

20. N. K. Kondrasheva, A.M. Eremeeva\& K.S. Nelkenbaum. 2018. Development of domestic technologies of produsing high quality clean diesel fuel.

Izvestiyavysshikhuchebnykhzavedeniikhimiyakhimi cheskayatekhnologiya, 61(9-10), 76-82. https://doi.org/10.6060/ivkkt.20186109-10.5651

21. N. K. Kondrasheva, A. M. Eremeeva, K. S. Nelkenbaum, O. A. Baulin\& O. A. Dubovikov. 2019. Development of environmentally friendly diesel fuel, Petroleum Science and Technology, 37:12,
1478-1484, DOI: 10.1080/10916466.2019.1594285

22. O. Cheremisina; V. Sergeev; V. Alabusheva; A. Fedorov; A. Iliyna. The Efficiency of Strontium-90 Desorption Using Iron (III) Solutions in the Decontamination Process of Radioactive Soils. Journal of Ecological Engineering WOS:000428724900017. 2-s2.0-85042483092. 2018 (No. 2, V. 19, 2018. P 149-153.)

23. Berlinskii\& A. Kuzhaeva. 2017. The study of the mechanism of the oxidative desulphurization. In International Multidisciplinary Scientific GeoConference Surveying Geology and Mining Ecology Management, SGEM (Vol. 17, pp. 1001-1008). https://doi.org/10.5593/sgem2017/51/S20.037

24. Semenyutina\& A. Klimov. 2018. Analysis of bioresources of the gene pool of Robinia, Gleditsia for forest meliorative complexes on the basis of studying adaptation to stress factors. World Ecology Journal, 8(2), 33-45.

https://doi.org/https://doi.org/10.25726/NM.2018.2. 2.004

25. Semenyutina, I. Svintsov, A. Huzhahmetova\& V. Semenyutina. 2018. Regulation of increase of biodiversity of woody plants in protective forest plantings of the Volga region. World Ecology Journal, 8(2), 46-59.

https://doi.org/https://doi.org/10.25726/NM.2018.2. 2.005

26. Tereshkin. 2018. Specificity of optimization of recreational potential Forest park (on the example of the green zone of Saratov). World Ecology Journal, $8(2), 60-70$.

https://doi.org/https://doi.org/10.25726/NM.2018.2. 2.006

27. Mohmand, M. I., Bhaumik, A., Humayun, M., \& Shah, Q. (2019). The performance and classifications of audio-visual speech recognition by using the dynamic visual features extractions. International Journal of Advanced Trends in Computer Science and Engineering, 8(5), 2049-2053.

https://doi.org/10.30534/ijatcse/2019/31852019

28. Sudha, V., Mohan, S., \& Mohan, R. M. (2019). A high performance on extemporize yield of horticulture crops with predictions based water and soil properties using multivariate analytics and machine learning algorithms. International Journal of Advanced Trends in Computer Science and Engineering, 8(4), 1706-1710. https://doi.org/10.30534/ijatcse/2019/98842019 